Artigos

ENCARTE DIGITAL

\title{
Cidadania, reconhecimento e ação afirmativa no ensino superior
}

\author{
Citizenship, recognition and affirmative action \\ in higher education
}

Angela Randolpho Paiva*

\begin{abstract}
Resumo: O presente artigo analisa a implantação das políticas de ação afirmativa nas universidades públicas à luz dos principais conceitos que ajudam na compreensão das mudanças ocorridas no acesso ao ensino superior entre 2002 e 2012. Enfatiza a redemocratização, ação do movimento negro e a controvérsia em torno da adoção das "cotas raciais". Assim, conceitos como cidadania, esfera pública, direitos, reconhecimento, ação coletiva e identidade serão aqueles privilegiados na análise, pois têm grande validade heurística para se entenderem as mudanças ocorridas no acesso ao ensino superior em direção a sua maior diversidade e inclusão social. Mostra como, em um período de dez anos, mais de $70 \%$ das universidades públicas enfrentaram desafios para sua transformação em uma instituição que incorpore a ideia do direito social do acesso à educação de forma mais substantiva.
\end{abstract}

Palavras-chave: Cidadania. Ação afirmativa. Reconhecimento. Movimento negro. Esfera pública.

Abstract: The present article analyses the implementation of affirmative action policies in Brazilian public universities by using the most important concepts that help shed light to understand the main changes in the access to higher education between 2002 and 2012. It emphasizes the re-democratization of the country, the action of the black movement and the controversy about the "racial quotas". Therefore, concepts such as citizenship, public sphere, rights, recognition, collective action and identity have great heuristic value in the understanding of the changes that have taken place in the access to higher education towards greater diversity and social inclusion. It shows that in a ten year period over $70 \%$ of public universities have faced challenges towards their transformation in an institution that effectively incorporates the idea of education as a social right.

Keywords: Citizenship. Affirmative action. Recognition. Black movement. Public sphere.

\footnotetext{
* Doutora em Sociologia pelo Instituto Universitário de Pesquisas do Rio de Janeiro (Iuperj, Rio de Janeiro, RJ, Brasil), professora do PPG em Ciências Sociais da Pontifícia Universidade Católica do Rio de Janeiro e líder do grupo de pesquisa do CNPq "Direitos, reconhecimento e desigualdade"; é coordenadora central de cooperação internacional (CCCI) da PUC-Rio <apaiva@puc-rio.br>.
}

Civitas, Porto Alegre, v. 15, n. 4, e127-e154, out.-dez. 2015 


\section{Introdução}

A discussão atual acerca da ação afirmativa no ensino superior representa um momento exemplar para a reflexão sociológica em torno de algumas das mais caras categorias analíticas da teoria social. Implica primeiramente na revisão do que se entende por cidadania, construída no Brasil em uma chave cuja marca registrada é a persistente desigualdade na sua formação social. Requer também trazer uma discussão atualizada sobre a esfera pública, no momento em que se deu a redemocratização do país, em especial os anos 90, quando antigos e novos atores surgem demandando direitos postergados, não reconhecidos ou negados. Como consequência desse processo, significa ainda analisar o potencial dos movimentos sociais no que concerne às novas demandas colocadas na esfera pública, quando pautam uma nova agenda política nessa esfera mais receptiva a reivindicações porquanto mais democrática. Traduz também a necessidade de discutir a questão das identidades coletivas e a luta pelo reconhecimento, no sentido dado na tradição hegeliana do reconhecimento intersubjetivo, e analisado por Honneth no que este padrão resulta na interação das práticas sociais em sua "gramática dos conflitos morais". Demanda, por último, a reflexão sobre a ideia de ação afirmativa e a controvérsia que envolve tais políticas, que vão necessariamente interferir nas estruturas da organização social existente. Isso ajuda a entender a animação da esfera pública brasileira, cujo acordo societário logrado não foi capaz de oferecer as condições mínimas de atribuir o mesmo princípio de dignidade a todos os seus grupos sociais.

$\mathrm{Na}$ discussão que segue, serão destacados os dilemas da construção da cidadania em uma sociedade tão desigual quanto a brasileira, destacando-se os seguintes aspectos: a ambiguidade das relações raciais no Brasil, cuja marca de origem é a desigualdade concentrada na população negra; a importância do surgimento do movimento social negro profundamente ligado ao processo de redemocratização do país; e o processo que se deu para que fosse possível o surgimento das políticas de ação afirmativa para negros no ensino superior. Parte-se da premissa de que ação afirmativa vai ser sempre objeto de polêmica, na medida em que implica o fim da "neutralidade estatal", como lembra Joaquim Barboza (2001), uma vez que elas saem do nível da prescrição formal da promessa de direitos para serem pensadas como direitos substantivos, que pedem políticas de inclusão que visem a efetiva igualdade de oportunidades para todos. No caso da ação afirmativa no ensino superior para a população que se autodeclara negra, esse recorte se impõe porque a grande controvérsia não é mais a ideia de políticas de ação afirmativa em si, uma vez que a maior parte das políticas de acesso ao ensino superior pensada para alunos egressos 
do ensino público já é bastante aceita pela sociedade, como vai ser mostrado mais adiante, e políticas de ação afirmativa no mercado de trabalho ou nos partidos políticos não suscitam tamanha discussão. Mas o que está na mídia, e também na discussão acadêmica, é o processo metonímico que toma a questão das "cotas" para "negros" como se fosse um todo no que se refere aos grupos aí incluídos. Cota é uma das políticas de ação afirmativa pensadas, ao lado de outros tipos de políticas para vários outros beneficiários, sendo os negros um dos grupos beneficiados. ${ }^{1}$

Temos, assim, presenciado um intenso debate na arena discursiva da esfera pública, como definiria Habermas o momento em que novos argumentos são levantados nos espaços públicos discursivos com o objetivo de questionar as crenças centrais que predominaram nas relações raciais do país. E é nos espaços públicos discursivos que indivíduos com paridade para interagirem na esfera pública são capazes de trazerem novos argumentos que, em última análise, possam repensar o que se entende por um projeto de sociedade. ${ }^{2} \mathrm{E}$ foi o que aconteceu com a discussão sobre a adoção de ações afirmativas nas universidades públicas e muito se tem escrito sobre os argumentos favoráveis ou contrários às políticas de ação afirmativa na universidade pública. A presente análise vai defender que tais políticas significam repensar a universidade pública brasileira como instituição, uma vez que ação afirmativa representa o esforço de interferir na desigualdade estrutural do sistema de ensino público superior no que se refere aos grupos que o frequentam.

O objetivo do presente artigo é, primeiramente, trazer o foco para a chave da fruição de direitos humanos e para a construção da cidadania no Brasil, no sentido de ver quais foram os mecanismos utilizados para que a cidadania pudesse ser realizada em uma chave tão desigual, chave na qual a população negra está super-representada. Será dada ênfase às ideias fortes que prevaleceram no nosso imaginário social, para que essa desigualdade fosse naturalizada e pudesse obter a aquiescência daqueles que se mantiveram em situação de subalternidade. Em um segundo momento, serão destacados alguns fatores que foram determinantes para a organização de movimentos

\footnotetext{
${ }^{1}$ Cota foi a primeira política pensada para egressos da escola pública, negros e pessoas com deficiência, junto com a modalidade de acréscimo de vagas, pensada para um público-alvo específico, os indígenas. O acréscimo de pontos foi iniciado com a Unicamp, em 2005.

${ }^{2}$ Ressalta-se aqui a validade heurística do conceito de esfera pública de Habermas no que diz respeito a esse requisito básico de um mínimo de igualdade para a participação na esfera pública. Apesar de ter sido criticado quando há mais de quatro décadas pensou o conceito - uma esfera pública burguesa, branca e masculina. $\mathrm{O}$ autor depois fez grandes contribuições para o desenvolvimento deste conceito, tanto na sua teoria da ação comunicativa, quanto em textos em que analisa os movimentos sociais, em especial o feminismo.
} 
sociais negros, que vieram denunciar algumas dessas ideias fortes que estavam cristalizadas no nosso imaginário social, em particular a existência de racismo. E a discussão sobre reconhecimento na sua dimensão política assume importância especial para se compreenderem as novas formas de ação coletiva, em especial no momento de redemocratização. Esses dois pontos ajudam a compreender, em um terceiro momento, tanto as novas demandas que estão postas na esfera pública sobre ação afirmativa no ensino superior, quanto as mudanças ocorridas entre 2002 e 2012.

A contextualização e conceituação dos direitos e demandas por reconhecimento ajudam na problematização de um debate que trata de um tema complexo e permeado por disputas. Mas fica registrada a consciência de que, longe de esgotar suas possibilidades analíticas (afinal, como diria Weber, a realidade social é complexa demais para querermos interpretá-la em todas as suas dimensões), o que vai ser tentado a seguir é ver alguns dos fatores que explicam a "mudança estrutural da esfera pública" brasileira dessa última década, no que concerne aos movimentos negros e à configuração do ensino superior público.

\section{Cidadania moderna: rearranjos na esfera pública}

O ideário republicano brasileiro de cidadania tem como pilares os mesmos princípios de igualdade e liberdade inscritos nas constituições liberais pensadas naquelas sociedades que lograram um maior projeto de inclusão a partir do século 20, cujo princípio norteador é a igualdade prescrita na lei. A concepção de cidadania - analisada por Marshall ao pensar nas conquistas dos diversos tipos de direitos na Inglaterra - foi vista como o ideal a ser alcançado para que a igualdade mínima de participação na esfera pública pudesse ser realizada. Esta foi a condição assinalada por Habermas e Hannah Arendt como sine qua non para que tal participação fosse possível, trazendo consigo um novo status que independesse das classes sociais aos quais os indivíduos pertenciam. ${ }^{3} \mathrm{E}$ vários aspectos podem ser destacados para que se entenda a gênese da cidadania moderna e a complexidade de sua tradução para a análise da formação social brasileira.

Como primeiro ponto, a concepção moderna de indivíduo das sociedades ocidentais é fundamental nessa construção, cujos valores inerentes para sua existência são a autonomia, a privacidade, a igualdade e a dignidade. São

\footnotetext{
${ }^{3}$ Marshall (1967) acreditava que o status da cidadania chegara para mitigar as desigualdades de classe geradas pelo sistema capitalista. Interessante notar que o autor era extremamente otimista na época em que escreveu seu texto clássico no período do pós-guerra, com a consolidação dos direitos sociais que vinha se realizando em vários países europeus.
} 
valores que levaram à profunda reorganização nas relações sociais e vão operar mudanças radicais na configuração do estado-nação para que eles possam ser realizados. Trata-se, assim, do processo da construção de "identidades individualizadas", como propõe Taylor (1994), que implica em um modo de ser particular que emergiu a partir da reordenação dos arranjos sociais, tendo como princípio basilar o valor da dignidade igual, mas sempre construído na sua dimensão dialógica.

A emergência desse indivíduo portador de direitos se dá no processo de interação social, cuja identidade se realiza no processo dialógico, e resulta no que Appiah (1994) vai chamar de "identidades coletivas", ou seja, o momento em que se logra um grau mínimo de concertação social capaz de prover scripts positivos para a realização da "autenticidade" dos indivíduos em interação social. Isto significa ainda dizer que pode surgir o momento de concretização de formas de resistência que lutem contra forças sociais conservadoras e que propiciem novas formas de luta por reconhecimento. Essa identidade coletiva vai ser fundamental para a construção social da cidadania moderna nos diversos estados-nação, fundando-se em valores que representaram uma profunda reorganização da ordem social, e que levaram mesmo à mudança de se entender o acordo social nas várias nações do mundo ocidental. Em décadas mais recentes, tem-se ampliado o leque de reivindicações, trazendo para a esfera pública demandas pautadas em novas identidades individualizadas, tais como gênero, sexo, raça, etnia ou religião, dentre outras.

Mas a concepção de indivíduo em interação social implica em uma segunda dimensão: a participação na esfera pública, que deve estar relacionada à possibilidade da realização da solidariedade social, para que possa ser possível o próprio processo de participação. Partiria, sem dúvida alguma, da "identidade individualizada", mas é necessário, como indica ainda Taylor, o caráter de uma identidade dialógica para sua construção. Nesse processo, a linguagem no sentido amplo de processo de interação com outros, requer a realização da "fruição comum" para que a própria identidade seja reconhecida. E Taylor lembra a pertinência da análise de Mead (1992), que chamou de generalized others o pacto social realizado pela solidariedade social no sentido mais radical, na percepção do seu envolvimento com grupos sociais impessoais. Os "outros generalizados" extrapolam os primeiros grupos primários, ou seja, o mundo das relações familiares, que o autor chama de significant others, para que seja possível a construção da ordem social mais ampla. A solidariedade social assume, portanto, dimensão bem distinta da solidariedade cristã, na qual está embutida a ideia de filantropia e ação assistencialista. Esse modelo implicou em um projeto de nação no qual a exclusão de grandes segmentos 
da sociedade se tornou uma questão social: no século 20 houve grande avanço na inclusão daqueles antes excluídos de qualquer participação, sendo a universalização da educação básica elemento fundante para a realização da integração social mínima.

Assim sendo, a análise dos distintos pactos sociais nos leva a outro aspecto analítico importante de ser enfatizado, qual seja, a necessidade de contextualização da realização dos direitos humanos para sua fruição efetiva, não podendo estes ser entendidos na sua forma abstrata. Como lembra Bobbio (1990, p. 24), "o problema filosófico dos direitos do homem não pode ser dissociado do estudo dos problemas históricos, sociais [...]". A contextualização se impõe na teoria social para que as diversas formas que os direitos civis, políticos, sociais e culturais apresentam nos vários contextos nacionais possam ser analisados. E é dessa perspectiva que direitos humanos vão ser entendidos aqui: como constructo social sujeito a constantes mudanças e formas heterogêneas de realização, sempre relacionados à contingência histórica para a realização dos vários tipos de direitos, e que funcionam ainda como reguladores das práticas sociais (Telles, 1994). Para que tal processo se realize, é preciso uma esfera pública democrática cada vez mais diferenciada.

Nessa concepção universalizada de cidadania está ainda implícito um quarto aspecto relevante, vale dizer, a igualdade mínima para a participação na esfera pública, como defende Hannah Arendt (1983). É, em última análise, o direito a ter direitos, a exigir constantes demandas para o alargamento da esfera pública. E se antes esta era a esfera pública burguesa, como descreveu Habermas (1984), ao analisar o surgimento dos cafés literários e saloons do século 18 como o início da sociabilidade em lugares de troca e de comunicação de indivíduos (burgueses) autônomos, pode-se dizer que as democracias modernas trouxeram a constante recriação da esfera pública, numa ampliação que significou a inclusão de vários outros segmentos da sociedade que dela não participavam, como é o caso da classe operária, até o final do século 19, e das mulheres que somente lograram participação efetiva no século $20{ }^{4}$

É por essa razão que Hannah Arendt e Habermas vão falar de uma esfera social, no momento em que a participação na esfera pública é feita com os direitos individuais salvaguardados pelo estado. O ideário dos direitos humanos, no que se refere aos princípios aí contidos, é que vai ser o norte

\footnotetext{
${ }^{4}$ Seyla Benhabib (1999) diferencia os modelos de esfera pública de Hannah Arendt e Habermas, lembrando que para a primeira é um modelo de espaço público agonístico, como a realização da virtude cívica, enquanto para Habermas pode ser o espaço discursivo de reconstrução democrática onde os indivíduos estão engajados em discursos práticos, numa avaliação constante de suas validades.
} 
para as demandas ocorridas nessa esfera pública burguesa dos séculos 18 e 19, sendo inspiradores dos vários movimentos sociais ocorridos no século 20; vai ser fundamental tanto para as políticas distributivas pensadas nos estados modernos, quando estes passam a assumir funções estruturantes para a regulação dos direitos conquistados, como para as posteriores demandas por reconhecimento de grupos invisibilizados. Para que tal processo se realize, há sempre o pressuposto de uma igualdade mínima para viabilizar a participação na esfera pública, que não é apenas política, como lembra o próprio Habermas (1984), mas também social ou cultural.

Todos esses aspectos convergem para a questão do processo da constante ampliação de direitos na luta por ação coletiva dos movimentos sociais. Tratase da construção de identidades que chegam para pedir o reconhecimento de legítima participação no espaço público, que pode significar o caminho para um projeto cada vez mais universalizado de cidadania. São duas concepções que podem, a princípio, ser consideradas contraditórias: afinal, universal tende a ser homogêneo, igual, mas o caráter universalizante da cidadania não pode ser tomado como uma pretensão à homogeneidade dos indivíduos que fazem parte do consenso social. Muito pelo contrário, com a crescente diferenciação das sociedades contemporâneas, que alguns autores chamam de "pós-modernidade" (Hall, 2005), o universal deve englobar estas várias possibilidades de ser cidadão, na formação de "espaços públicos", como analisa Nancy Fraser (1997), as novas formas de concertação social que não passam pelas chaves clássicas de classe social e partidos políticos. Assim, se até a década de 1960, a concepção de cidadania tinha o caráter homogeneizante de direitos iguais para todos, com a crescente demanda de novas identidades trazida pelos movimentos sociais que surgiram a partir de então, passa a ser necessária uma nova equação entre igualdade e diferença, como aponta Iris Young (1989). No entanto, a ideia de cidadania não prescinde daquele mínimo de igualdade que é necessário para que as diferenças possam ser reconhecidas como válidas, exigindo, portanto, a necessidade mais complexa de se equacionar igualdade com o direito à diferença.

Nancy Fraser, em outro texto (2003), enfatiza que a luta pelo reconhecimento e o pedido de redistribuição não são concepções excludentes, mas que se referem à dupla dimensão que compõem a noção de justiça social, e que podem levar à equidade para a paridade de participação de que se falava acima: "Whether they are demanding redistribution or recognition, claimants must show that the social changes they seek will in fact promote parity of participation" (2003, p. 38). Fraser (2002), concordando com Taylor, enfatiza ainda a ideia da conquista de status, no sentido dado por Weber, 
para se entender a questão do reconhecimento, quando os "grupos de status" são definidos pelas relações de reconhecimento de sua posição social e não apenas pelas reivindicações redistributivas contidas nos conflitos de classe. E é o que se tem assistido com a emergência dos mais diversos movimentos sociais contemporâneos: a afirmação de diferenças, mas tendo como objetivo o reconhecimento de seu igual valor e legitimidade de sua demanda na esfera pública mais ampla.

A análise feita por Axel Honneth (2003) ajuda a matizar o que se deve entender por reconhecimento - e a falta dele - em uma perspectiva sociológica. Ele quer entender como se dá a "gramática moral dos conflitos sociais". Inspirando-se em Hegel e Mead, o autor trabalha com três padrões de reconhecimento intersubjetivo, baseados (a) no amor/amizade, (b) nos direitos (dimensões analisadas por Hegel) e (c) na solidariedade (discussão feita por Mead). Essas dimensões correspondem a um determinado resultado nas interações sociais, vale dizer, a autoconfiança para o primeiro, o autorrespeito para o segundo, e a autoestima para o último. A violação às três formas de reconhecimento se traduz em formas de desrespeito, respectivamente de (a) maus-tratos e violação, (b) privação de direitos ou exclusão e (c) degradação e ofensa. Na personalidade violada, isso se reflete na integridade física, na integridade social e na dignidade da pessoa.

Estas são as bases que Honneth (2003, p. 255) lança mão quando se recusa a interpretar as formas de protestos e formação de movimentos sociais apenas na chave do interesse. Defende que uma teoria social de teor normativo "depende, sobretudo, de um conceito de luta social que toma seu ponto de partida de sentimentos morais de injustiça, em vez de constelações de interesses dados". Este é um dos seus principais objetivos: entender a "ponte semântica" entre as finalidades impessoais de um movimento social e as experiências privadas que os participantes têm das formas de desrespeito, pois é a partir daí que pode se constituir em uma identidade coletiva. Assim, é dada a partida para tirar esses indivíduos do "rebaixamento passivamente tolerado", restituindo, assim, parcialmente a autoestima (p. 259). ${ }^{5}$

$\mathrm{O}$ argumento de Honneth, de que o não reconhecimento é o elemento perverso para a manutenção de relações subalternas e de que é preciso entender o momento em que se dá o processo de recusa dessa subalternidade com a superação da autoestima violada, é central para a compreensão da formação

\footnotetext{
${ }^{5}$ Há intensa literatura sobre reconhecimento que foge ao escopo do trabalho, inclusive a troca de pontos de discordância entre Fraser e Honneth (2003). Para a interpretação desses dois autores e de Charles Taylor, ver Patrícia Mattos (2006). Ver Nythamar de Oliveira (2009) para conceitos centrais relacionando reconhecimento e ações afirmativas.
} 
de um movimento social. No caso dos movimentos negros brasileiros, a consciência da condição de sua subalternidade vai ser fundamental para a concertação da ação coletiva que emerge no final da década de 1970, momento definido por McAdam (1999) como o de "liberação cognitiva", quando novos marcos de referência (frames) são elaborados no processo político para que possa ser possível o engajamento para a ação coletiva. No caso do movimento negro brasileiro, figuras históricas como a Abdias do Nascimento juntam-se para a construção de novas interpretações a partir do pensamento negro. ${ }^{6}$

\section{A cidadania disjuntiva brasileira}

Os aspectos descritos acima compõem uma dimensão ideal-típica da cidadania e nos ajudam a analisar a construção da cidadania no Brasil, no sentido de compreender algumas questões acerca da especificidade da nossa construção social. Ainda que o ideário de indivíduo portador de direitos descrito acima tenha sido o referencial para a concepção de todas as cartas constitucionais brasileiras concebidas na história da nossa República, ele foi pensado em uma sociedade cujos padrões de organização social eram bem distintos, sendo sua marca de origem a enorme desigualdade social. Tal organização recebeu um legado da ordem social escravocrata e com forte concentração fundiária, herdado de séculos anteriores, não havendo o processo de ruptura necessário para que houvesse a "mudança estrutural da esfera pública" brasileira.

E pode-se perguntar: de que forma visões de mundo tão opostas puderam conviver no pacto republicano nascente sem que tivesse havido as rupturas verificadas em outros cenários que passaram pelo processo de construção nacional com o valor fundante do indivíduo cidadão descrito acima? Dentre os traços predominantes dessa organização social, vão ser destacados alguns que foram decisivos para a formação de uma ordem social ambivalente e desigual, porém harmoniosa, a perdurar por várias décadas do século 20: a) primeiramente, manteve-se a hierarquização na ordem social, antítese do que se falava acima a respeito da igualdade como pressuposto para a participação na esfera pública (DaMatta, 1993); b) também ficou preservada a organicidade na concepção de mundo, ou seja, cada um no seu lugar, ainda que de forma desigual, com uma Igreja Católica romana pré-conciliar a espiritualizar essa desigualdade (Paiva, 2003), bem distinto do status nivelador da cidadania moderna; c) igualmente persistiu o paternalismo nas relações sociais, que

\footnotetext{
${ }^{6}$ Ver Quilombismo, de Abdias do Nascimento (2009), que exemplifica bem a construção em curso no final dos anos 70 .
} 
atenuou os padrões de desigualdade (Velho, 1996), imprimindo uma relação de patronagem longe do que se falava acerca da possibilidade de busca de autonomia do indivíduo; d) por último, foi cultivado o autoritarismo na esfera pública, resultado da apropriação do público pelo privado, cuja consequência política mais visível foi a formação de um estado que vai ser a concretização de todas as características anteriores (Reis, 1982).

São várias as interpretações no pensamento social brasileiro que procuram responder a essas questões e que partem de distintas tradições. Mas elas convergem para explicar a gênese da desigualdade social no que esta significou como impedimento para a efetiva fruição da cidadania, cujos princípios norteadores, como vistos acima, são a universalização dos direitos, a consciência de seu status de cidadão, a igualdade mínima assegurada, e a possibilidade de participação social. No Brasil, houve um processo de "modernização seletiva", como analisa Jessé Souza (2000), a criação de um estado moderno no qual não se mexeu com a "configuração valorativa da sociedade como um todo" (p. 246), visto que camadas da sociedade foram incluídas no processo de modernização enquanto outras ficaram relegadas à "condição secular de párias rurais e urbanos". Assim, a chegada de um ideário iluminista numa ordem social excludente e pouco afeita à mudança fez com que, mais do que "fora do lugar", como apontou Schwartz (1992), essas ideias fossem de exclusividade de uso daqueles grupos aos quais era permitido o acesso aos bens sociais. Nesse processo de modernização seletiva de estadonação, surge com a República o papel protagônico do estado para regular quem era cidadão (Santos, 1979; Carvalho, 1991) para um povo "bestializado" no que se refere aos seus direitos de cidadania, duramente reprimido em várias tentativas de mobilização. Como mostra José Murilo de Carvalho, a República não trouxe a participação através da organização de interesses em uma sociedade muito pouco escolarizada, não surgindo, assim, associações que pudessem representar segmentos para a consolidação de uma sociedade civil engajada. As existentes tinham caráter religioso ou eram organizações de festas populares.

Hierarquia, paternalismo, autoritarismo são, portanto, traços que vão marcar tanto os espaços de sociabilidade na sua dimensão cultural, quanto na sua dimensão política, gerando um deficit de participação na esfera pública, esfera de poucos e com enorme índice de exclusão, a começar pelas altas taxas de analfabetismo. A permear essa cultura política em formação houve ainda o dilema da burguesia nacional moderna que teve de estar em relações comprometidas com esse estado autoritário e com as forças do atraso nacional, fazendo uma "revolução passiva", uma "modernização a conta-gotas", como 
bem descreve Werneck Vianna (1997) o binômio conservação-mudança que vai ser o padrão até a redemocratização do país. Como consequência da formação que mesclou elementos tradicionais com elementos modernos, impulsionado ainda pelo crescimento econômico acelerado ocorrido entre as décadas de 1930 e 1970 que trouxe a urbanização e o crescimento dos setores médios, foi construído um padrão complexo, de elementos modernos em tensão com tradicionais, resultando na manutenção de uma ordem social pouco afeita à mudança e de base difícil para a efetivação de uma cidadania universalizada. São interpretações nas quais fica evidente que a nossa história republicana apresentou ambiguidades e paradoxos para a construção de uma ordem social democrática que pudesse contemplar a efetiva equalização dos direitos, uma vez que persistiram altos índices de desigualdade social. ${ }^{7}$

Mas como equacionar tamanha desigualdade social com a promessa republicana de igualdade? Que mecanismo é acionado para que se aceitem os índices da desigualdade social brasileira? Pode-se dizer que foi desenvolvida uma esquizofrenia social (Paiva, 2004), ou seja, a construção de visões de mundo distintas no processo de modernização seletiva, com a separação da visão de mundo correspondente a estas duas realidades: aos que têm acesso e aos que permanecem nas margens dessa esfera pública excludente. Esses últimos, até bem pouco tempo, eram mantidos numa organização social com mecanismos de uma ordem hierarquizante e patriarcal, cada qual no seu lugar, num padrão de subserviência e de "cordialidade", modelo esfacelado com a forte urbanização e substituído por outras formas de sociabilidade, inclusive mais violentas (Velho, 1996). O primeiro grupo foi o segmento dos brasileiros que logrou a modernidade constituída de várias faces: a econômica, a jurídica, a cultural e a tecnológica, enquanto o segundo, daqueles que estão fora do pacto social, é visto como um grupo difuso e ameaçador para os que estão dentro. Mas o padrão de dominação das nossas relações sociais é tão eficiente que a meritocracia, ideia forte e compartilhada por todos os segmentos da sociedade, ajuda na naturalização dessa ordem social desigual, visto que prevalece a ideia do mérito pessoal, e o "outro" se auto exclui ou se culpa por seu fracasso pessoal.

São dois mundos que se constroem à parte, e nessa esquizofrenia social - "o nosso" e o "outro" - há o cultivo de valores distintos em face de situações idênticas, como é o caso da relevância que se dá aos inúmeros

\footnotetext{
${ }^{7}$ Certamente há inúmeras nuances nessa análise que sairiam do escopo do objeto proposto aqui. Fica registrada a convergência das análises mencionadas, pese as matrizes teóricas distintas, para a compreensão de uma formação social ambivalente e paradoxal.
} 
exemplos de atos de violência perpetrados contra os "nossos", que aparecem personalizados e com visibilidade na mídia. Como resultado, pode-se falar com Durkheim de uma patologia, e essa patologia, juntamente com seus atenuantes, paternalismo nas relações sociais, misticismo religioso na visão de mundo, dentre outros, permitiram enorme sobrevida da desigualdade na nossa experiência republicana. Logrou então a formação de uma esfera pública excludente e superposta por interesses privados; uma ordem jurídica formal a prometer sempre maior justiça em um futuro impreciso; uma ordem social injusta que o desenvolvimento econômico viria, um dia, chegar para resolver todos os males; e finalmente uma ordem política autoritária, a privilegiar mecanismos de forte controle social, inclusive militar, nos momentos em que ocorreram conflitos em proporções que a sociedade brasileira (a incluída) não podia suportar. Nessa visão esquizofrênica, o "outro" sempre apareceu como um grupo social nebuloso, cujas demandas precisam ser reprimidas para que o "nosso" possa seguir na realização de uma cidadania disjuntiva.

E a maior parte da população negra pertence a esse "outro" grupo, vivendo dramaticamente o padrão de modernização seletiva descrito acima. Foi uma população que teve sua condição de cidadania ignorada no que se refere às políticas públicas específicas para que lhe fosse possível alcançar o status da cidadania. Logo após a Abolição, não houve políticas pensadas para a numerosa parcela da população negra que vivia à margem da organização social do Império, grande parte na condição de escravo. Muito pelo contrário, foi um momento de forte incentivo à imigração (imigração branca, europeia de algumas nacionalidades para "embranquecer" a nação), quando os negros foram relegados a sua própria sorte, com a promessa de que, num futuro impreciso, a prescrição formal da Constituição republicana de igualdade e liberdade seria realizada. Iniciou-se, assim, a construção no nosso imaginário social da ideia de que algumas qualidades são adstritas à raça negra, tais como a indolência, a malandragem e, por conseguinte, a falta de atitudes proativas necessárias para a formação de um cidadão, segundo Florestan Fernandes (1978). ${ }^{8}$

Assim, nossa formação republicana trouxe, com a produção estrutural da desigualdade social de que se falava acima, um padrão de desvantagens específico para a população negra pela falta de políticas públicas. Ao não conceberem políticas que pudessem alargar o pacto social brasileiro, os

\footnotetext{
${ }^{8}$ Giralda Seyferth (1996) faz a análise sobre a falta de preocupação com o destino da população escrava, assim como a desqualificação do mestiço para o trabalho independente. Ver Pereira (2008) e Gonzalez e Hasenbalg (1982) para a análise da situação dos negros a partir da República e suas formas de organização.
} 
arquitetos da nossa república empurraram a população descendente de escravos para a margem do acordo republicano, que passou a ocupar os postos de trabalho menos qualificados ou sobrevivendo no mercado informal. Isso fica visível ainda hoje quando se analisam os principais indicadores sociais de medição da desigualdade social, renda e escolaridade, que denunciam que a população negra brasileira não teve as mesmas chances de compartilhar o repertório de direitos (Hasenbalg e Silva, 2003; Henriques, 2001). Há, é claro, exceções dentre aqueles cuja ascensão social era obtida no sistema de patronagem, como analisou Emília Viotti da Costa (1977), e que pagavam um alto preço por esse passing, pois era preciso negar sua ascendência negra e se tornavam "pretos de alma branca". A ascensão social se deu por caminhos individuais e foi certamente um fator fundamental para alimentar o mito da nossa democracia racial.

A naturalizar tudo isso está, de um lado, o mundo hierarquizado de que fala DaMatta (1993, p. 68), quando, discordando de Gilberto Freyre sobre a harmonia racial construída pelo colonizador português, enfatiza que tais relações se sustentavam em relações complexas mas com a superioridade do branco, resultando em um "racismo à brasileira" que permitia a conciliação de impulsos contraditórios de mudança e conservação. Por outro lado, e para o reforço dessa relação peculiar, é cultivada a ideia de harmonia racial, que vai manter ainda afinidade com o projeto de nação que estava sendo construído no país, principalmente com a urbanização e industrialização iniciada na década de 1930 por Vargas. A partir desse período, houve forte ênfase na construção da ideia de nação de uma só "raça", enfraquecendo a ideia da existência de racismo. Assim, pese a organização de várias entidades negras (nos anos 1930, A Frente Negra Brasileira), ou, no pós-guerra, o Teatro Experimental do Negro (TEN), fundado por Abdias do Nascimento, estas tiveram enorme dificuldade de transformar sua luta contra a desigualdade racial em uma causa abraçada pela população negra.

Defende-se, assim, que a mestiçagem, elemento fundante da nossa brasilidade e transformada por Freyre (1981) em elemento positivo da cultura brasileira, é um dos fatores que impediram a formação, de forma generalizada, de movimentos sociais de afirmação de identidade negra até épocas recentes. Afinal, há uma subjetividade na classificação da cor que passa também pela condição de classe. ${ }^{9}$ A perpassar tudo isso, e corroborando com

\footnotetext{
${ }^{9}$ A classificação racial é uma discussão complexa, mas tomada aqui a partir da classificação do movimento negro, que enfatiza a negritude do preto e do pardo da classificação do IBGE como identidade coletiva estratégica para a organização de novos marcos de referência. Para estudos sobre classificação racial, ver Petrucelli (2007) e Schwartzman e Silva (2012), dentre outros.
} 
o mito de democracia racial, prevaleceu a ideia de que a discriminação era apenas social, negando a discriminação racial, e que estaria resolvida com o desenvolvimento a ser realizado no futuro. Assim, quando Hasenbalg se pergunta (1979) como foi possível a aquiescência da população não branca à tamanha desigualdade, ele atribui a estas duas ideologias - da democracia racial e do desenvolvimento - os mecanismos que asseguraram uma enorme sobrevida à falta de participação dos negros nos nichos restritos do mercado de trabalho. Este último faz parte das "zonas duras" da sociedade, de que fala Sansone (1993), ou seja, os espaços impessoais do mercado de trabalho e das relações matrimoniais, e que são contrastadas com as "zonas moles", aquelas relacionadas à intensa sociabilidade nos espaços de lazer. Porque foram estas zonas moles - os espaços da sociabilidade no plano cultural - que ajudaram na criação da ideia generalizada de harmonia racial.

Mas não se pode ficar na análise genético-descritiva da origem de nossa desigualdade racial depois das mudanças políticas ocorridas a partir da década de 1980. Cabe considerar as possibilidades presentes com a redemocratização do país para uma maior equidade na esfera pública, e ver de que forma a concertação da comunidade negra vem questionar essas ideias fortes da harmonia racial e da desigualdade apenas social. E a discussão sobre reconhecimento traz grande validade heurística para a compreensão desse momento.

\section{Mudanças na esfera pública - nova luta por reconhecimento}

Dentre as várias mudanças em curso na esfera pública, duas trouxeram de fato uma chave modernizadora para sua mudança estrutural. A primeira foi dada com o processo de redemocratização do país a partir da década de 1980, década de intensa mobilização social e política, com novos movimentos associativos centrados nas associações de bairro, de favelas e de ONGs; seja nos movimentos de mobilização social (campanha das Diretas Já) e política, cujo ponto culminante foi a participação na Constituinte de 1987-1988. Eles trazem demandas reprimidas que tornaram visíveis os vários conflitos latentes dessa esfera pública excludente. A concretização das demandas de vários grupos de pressão no processo constituinte - negros, indígenas, mulheres, meio ambiente, dentre outros - foi a nova Carta de 1988, que vai, não só estimular a descentralização, dando maior ênfase às novas formas de participação social da sociedade civil, mas também manifesta, pela primeira vez, a preocupação com direitos difusos, vale dizer, os direitos de grupos específicos.

A segunda mudança está no surgimento dos movimentos sociais de diversos matizes, quando novas identidades coletivas reinventam o pre- 
sente (Melucci, 2001) e conflitos latentes são trazidos para a esfera pública. Esses movimentos traduzem tanto reivindicações antigas, como a reforma agrária ou o direito à moradia, que se inscrevem em demandas por redistribuição de bens sociais, como demandas novas, como o movimento gay, que luta pelo reconhecimento da autenticidade de que fala Taylor. Como lembra Fraser (2003), tanto o movimento negro quanto o de mulheres trazem os dois tipos de reivindicação: tanto do reconhecimento de sua identidade de ser negro ou de ser mulher, identidades invisibilizadas durante longo tempo, quanto de redistribuição dos bens sociais que foram subtraídos nesse processo de invisibilização. Identidade defendida aqui como uma categoria redefinida em termos de um campo relacional, como analisa Gohn a identidade política, tratada como uma ferramenta em construção, apropriada e modelada, pela qual os sujeitos sociopolíticos e culturais são mobilizados para serem incluídos (Gohn, 2010, p. 31),

Com os movimentos sociais surge, portanto, uma conjuntura de "quebra de consenso", como definiria Hannah Arendt, o pedido de mudança na esfera social brasileira desigual, autoritária e conservadora: novos atores cobram na esfera pública o reconhecimento de suas demandas, em um exercício de afirmação de sua autoestima. Os movimentos negros, que se organizaram em 1977 no "Movimento Negro Unificado", com ato simbólico realizado em São Paulo, lograram achar um consenso em torno de duas questões: a denúncia da discriminação racial e demandas por acesso aos bens sociais, em especial à educação e ao mercado de trabalho, além do acesso à justiça. Assim pese as enormes divergências e tensões dos movimentos negros, há uma demanda específica que fica mais clara com a redemocratização do país e são pensadas estratégias de organização específicas. Questiona, afinal, a secular restrição de participação na esfera pública. Não é tarefa fácil: é preciso criar mecanismos legais e legítimos para a negociação dos conflitos, assegurados por uma democracia que lentamente se liberta dos mecanismos de controle e repressão, tanto aqueles mais explícitos, como os mais sutis. Mas a ideia de cidadania e o repertório de direitos se tornam realidade possível com uma Constituição que veio assegurar novos direitos. ${ }^{10}$

É um momento, portanto, de novas possibilidades de articulação, fortalecendo a arena da interação discursiva pensada por Habermas. Nesse

\footnotetext{
${ }^{10}$ Fazendo um breve parêntese, cabe lembrar como importantes organizações da sociedade civil lograram fornecer espaços públicos essenciais para movimentos geradores de identidade quando a esfera pública estava sob o controle do regime militar. Foram várias organizações profissionais ou ainda as diversas pastorais que surgiram nas Comunidades Eclesiais de Base da Igreja Católica, no revival da sociedade civil de que fala Costa (2002).
} 
novo contexto, está colocado um dilema para a nova experiência democrática: equacionar os deficit sociais que estão presentes, frutos da herança de desigualdade, combinada com a demanda de uma cidadania "radical" como estratégia política de diversos setores da sociedade que se recusam sua subalternidade histórica (Dagnino, 1994). Depois de vinte e um anos de fechamento político, a discussão sobre a desigualdade racial brasileira trouxe à tona questões que estavam latentes. É o que Tarrow (1998) analisa sobre novas estruturas de mobilização política, quando novos marcos são elaborados em momentos de novas oportunidades políticas com a redemocratização do país. Tanto o estado quanto a sociedade civil têm papel fundamental nesse redesenho de relações.

As duas mudanças destacadas acima - a redemocratização do país e a emergência do movimento negro - vão ser o pano de fundo para que possa ser compreendido o terceiro e último ponto do presente trabalho, o surgimento de políticas de ação afirmativa. Tais mudanças representam momentos importantes no papel das instituições do estado e da sociedade civil para novos rearranjos na esfera pública. De um lado, por parte das instituições do estado, pode-se mencionar o reconhecimento inédito, ainda no governo de Fernando Henrique Cardoso, de que havia racismo no Brasil, com a recomendação (tímida) de que fossem pensadas ações afirmativas nos vários ministérios, no momento da criação da Secretaria dos Direitos Humanos; no Legislativo, vários projetos de lei estavam tramitando no Congresso e que visavam à adoção de ações afirmativas nas universidades e no mercado de trabalho. ${ }^{11}$

No que se refere à movimentação da sociedade civil, a década de 1990 vai ser palco de grande animação dos movimentos negros: diversos coletivos negros se organizam e promovem encontros nacionais (Encontro Nacionais de Entidades Negras ou Encontros Nacionais de Mulheres Negras), associações (Associação Brasileira de Pesquisadores Negros) e conselhos (Conselho Nacional para a promoção da igualdade racial) para citar apenas alguns. Essas ações culminaram com a Marcha de Zumbi dos Palmares, realizada em Brasília, em 1994, pela igualdade racial (cf. Pereira, 2008).

Cabe destacar ainda que as conferências das Nações Unidas - a de Direitos Humanos, em Viena, 2003, e a Conferência contra o Racismo, em Durban, 2001 - foram momentos aglutinadores essenciais para os vários movimentos

\footnotetext{
${ }^{11}$ No âmbito da ação legislativa, a década de 1990 vai representar intensos debates sobre a existência de racismo e de sub-representação da população negra, resultando em leis específicas, cuja inspiração estava na Carta de 88 , como a Lei Paim, que tornou o crime de racismo inafiançável e vários projetos de ação afirmativa no ensino superior. Várias propostas de lei que tratavam de ações afirmativas estavam nos legislativos estaduais nesse período.
} 
negros, que, superando os conflitos existentes nas distintas organizações negras, elegem questões estratégicas a serem demandadas na esfera pública. Em Viena, demandam direitos iguais, com atenção para mulheres (Ribeiro, 2014); em Durban, demandam políticas de combate ao racismo e políticas de ação afirmativa na universidade e no mercado de trabalho. Como ressaltam Heringer (2004) e Medeiros (2004), as reuniões prévias à Conferência de Durban foram apontadas como elemento aglutinador das inúmeras demandas então dispersas de vários grupos. ${ }^{12}$ Depois da Conferência de Durban, ficou o compromisso, explicitado quando o estado brasileiro assinou as declarações finais, de pensar ações governamentais que reparassem a desigualdade de acesso à educação e ao trabalho. O período pós-Durban trouxe ainda a visibilidade ao tema de políticas de inclusão social, e o debate sobre políticas de ação afirmativa é intensificado, tanto na esfera estatal, quanto na sociedade civil.

E como último ponto sobre as ações no âmbito da sociedade civil na década de 1990, é importante lembrar a criação de vários vestibulares comunitários, que trouxeram nova alternativa para que "negros e carentes" pudessem se preparar para o vestibular. Se antes essa preparação era restrita às classes média e alta pelo seu alto custo, os pré-vestibulares comunitários começam a qualificar novos candidatos para o vestibular em um processo lento, porém sustentado. Hoje são vários, organizados em associações, escolas, igrejas, universidades. E com as políticas posteriores pensadas pelo MEC, este acesso passa a ser uma realidade efetiva, uma vez que houve forte ação governamental para a expansão do ensino superior. ${ }^{13}$ Como resultado concreto da confluência trazida aqui, as políticas governamentais encontram uma parcela expressiva de jovens moradores da periferia ou de favelas que passaram a estar em condições mínimas de igualdade de chegar ao vestibular. ${ }^{14}$

Mas de que maneira essa discussão nos remete à terceira questão colocada inicialmente no que concerne ao acesso à educação superior para a popula-

\footnotetext{
${ }^{12}$ Ver o excelente trabalho de Verena Alberti e Amilcar Pereira (2007), com entrevistas feitas com as principais lideranças negras do país, no qual fica claro que a demanda por ação afirmativa vai ser a grande demanda nos anos 1990, tornando-se uma estratégia de consenso nos vários movimentos negros. Matilde Ribeiro (2014) faz detalhado estudo sobre as políticas de promoção da igualdade racial no Brasil e Sales Augusto dos Santos (2014) analisa a importância da educação no movimento negro.

${ }^{13}$ Desde 2005 o MEC tem pensado nessa expansão, que acarretou em mudanças profundas: em 2005 com o ProUni, programa de incentivo de acesso às universidades privadas com a renúncia fiscal por parte do governo, o que abriu novo leque de opções para o ingresso nas universidades; em 2007 criou o Reuni, programa que estimulava as universidades federais a se repensarem no que diz respeito tanto à inclusão, quanto à expansão do seu campus. Isso sem falar da consolidação e ampliação do Enem.

${ }^{14}$ Para a análise dos pré-vestibulares comunitários, ver Santos (2014), onde o autor traça a gênese desses cursos com corte racial que surgem em todo o país na década de 1990 e suas tensões.
} 
ção negra? Procurar-se-á mostrar a seguir que a atual discussão sobre as políticas de ação afirmativa é emblemática para vários dos pontos levantados aqui. Está sendo defendido que o período da redemocratização e a organização do movimento negro em torno de demandas específicas vão traduzir um momento de enriquecimento da esfera pública do país, cujas demandas passam principalmente pelo aceso à educação a partir da década de 1980, com uma demanda específica de ação afirmativa nas universidades públicas no final da década de 1990 .

\section{Ação afirmativa: uma demanda possível}

As desigualdades raciais no Brasil foram foco de estudos acadêmicos específicos desde a década de 1970. Naquele momento, Carlos Hasenbalg e Nelson do Valle Silva (1992, p. 99) mostraram a correlação perversa entre a desigualdade social e a cor da população brasileira, usando a cor como variável independente para a explicação das desigualdades de renda e escolaridade: "[...] a proporção de negros e pardos que não têm acesso à escola é três vezes maior que a dos brancos. Essas desigualdades não podem ser explicadas nem por fatores regionais nem pelas circunstâncias socioeconômicas das famílias." Acontecia o que estes autores chamam de "ciclo cumulativo de desvantagens" para os negros, uma vez que não só o ponto de partida já é de desvantagens, mas também os negros sofrem, a cada etapa de seu desenvolvimento, de novos constrangimentos provocados pelo racismo. Assim, entende-se a defesa de Antonio Sérgio Guimarães (1999), tempos depois, acerca da necessidade de se construir um conceito sociológico de "raça" que prescinda de qualquer fundamentação biológica para o entendimento das formas sutis do racismo brasileiro.

Mas se esses são estudos acadêmicos, iniciados na década de 1970, na década de 1990 vários estudos de órgãos governamentais, em especial do Ipea e do IBGE, vão mostrar que a desigualdade social tinha cor e continuava a persistir. A título de exemplo, se esses estudos demonstravam que a escolaridade média do brasileiro aumentou na década de 1990, mostraram também que a desigualdade entre brancos de um lado, e pretos e pardos de outro, se manteve a mesma. Vale dizer, houve um aumento de 2,2 anos na escolaridade média dos brasileiros para ambos os grupos, mantendo, assim, a mesma distância entre ambos (Henriques, 2001). As análises do Ipea e do IBGE têm maior potencial de divulgação e foram decisivas na construção de novas arenas discursivas de que se falava acima, especialmente para os acadêmicos que começaram a discutir a adoção de ações afirmativas nas universidades públicas, analisadas a seguir. ${ }^{15}$

\footnotetext{
15 A desigualdade racial foi um dos fatores mais importantes para que vários acadêmicos mudassem sua opinião sobre a implantação de ação afirmativa nas suas universidades.
} 
Esta é uma história longa e cheia de meandros e certamente estão sendo trazidas aqui apenas algumas das circunstâncias importantes que explicam a confluência entre atores, ação governamental e a produção de mudanças estruturais na esfera pública em geral, e no ensino superior em particular. É, portanto, um momento de profundas transformações no que se refere ao acesso à educação superior, tanto para os que se autodeclaram negros, quanto para os egressos das escolas públicas. Significa o primeiro momento em que uma ação efetiva vai buscar a parcial reparação do deficit de oferta da educação superior para a promoção de uma cidadania mais democrática. É o momento em que se tenta mitigar a situação perversa instalada no sistema educacional brasileiro: aqueles que têm condições de frequentar boas escolas (a maioria da rede privada, considerada de "excelência", e algumas da rede pública, também de excelência) são os que conseguem acesso à educação, gratuita e de qualidade, das universidades públicas. Como lembra Antonio Sérgio Guimarães, "o mercado e o governo discriminam duplamente o negro; primeiro, oferecem mais chances de qualificação para os estudantes oriundos de colégios privados; segundo, qualificam melhor os universitários da rede pública" $\left(2002\right.$, p. 68). ${ }^{16}$

Mas na década de 2000 a estrutura perversa de acesso ao ensino superior público passou a ser questionada. Fruto do processo descrito acima, 2002 foi um ano importante para se pensar em modificar o sistema estrutural desigual de acesso ao ensino superior. Naquele ano, as universidades do Estado do Rio de Janeiro (Uerj), do Norte Fluminense (Uenf), do Mato Grosso do Sul (Uems) e a Estadual da Bahia (Uneb) adotam o sistema de cotas. As três primeiras por indicação do legislativo estadual e a segunda por consenso da própria universidade. A partir daí iniciou-se intensa discussão nos conselhos universitários das universidades públicas em um processo no qual confluíam as leis em trâmite no Legislativo com as demandas dos Núcleos de Estudos AfroBrasileiros (Neab) de diversas universidades, juntamente com a ação direta de vários docentes. Assim, de 2002 até 2012, ano em que a Lei 12.712, que torna mandatória a adoção de politicas de ações afirmativas nas universidades federais até 2016, é sancionada, foi realizado um processo de implantação de políticas de ação afirmativa em mais de $70 \%$ das universidades estaduais e federais a partir de seus próprios conselhos universitários.

\footnotetext{
${ }^{16}$ Antonio Sérgio Guimarães lembra a deterioração do ensino público ocorrida nas últimas décadas, o que só aumenta o quadro perverso da desigualdade educacional do país. Dessa forma, a mobilidade social ocorrida de maneira vertiginosa no país em décadas passadas já não acontece da mesma maneira. Ver também Carlos Antonio da Costa Ribeiro (2006) para o estudo sobre raça e mobilidade social.
} 
É o que mostra a pesquisa "Monitoramento e acompanhamento das políticas de ação afirmativa nas universidades brasileiras", realizada na Puc-Rio, no âmbito do Núcleo Interdisciplinar de Reflexão e Memória Afrodescendente - Nirema - e financiada pela Finep. O grande objetivo era entender o que ocorria nas universidades federais e estaduais e para isso era preciso uma pesquisa de campo. O projeto se dividiu em três: a) análise permanente dos editais das universidades de todo o país que tinham adotado algum tipo de ações afirmativas; b) análise quantitativa com a aplicação de formulários junto a alunos dos cinco cursos mais e dos cinco menos procurados das universidades visitadas; c) análise qualitativa, com entrevistas junto a "gestores" (professores, coordenadores, pró-reitores, reitores) que estavam envolvidos com a implantação das políticas. Na primeira fase da pesquisa de campo, de 2006 a 2008, foram visitadas dez universidades federais e estaduais de todas as regiões do país que tinham adotado ações afirmativas há mais de dois anos. Na segunda fase, de 2009 a 2011, foram visitadas outras dez universidades, resguardando a proporção de universidades por região. Foram feitas entrevistas semiestruturadas com 57 gestores das 20 universidades selecionadas, com um roteiro de cinco itens: a) processo de implantação; b) impactos no campus; c) desafios apresentados; d) políticas de permanência pensadas para esse "novo" aluno; e) prospecção acerca das políticas. ${ }^{17}$

As políticas de ações afirmativas são variadas e o acompanhamento dos editais das universidades revelou-se de grande utilidade para entender as mudanças em curso, uma vez que a mesma universidade modificava seu processo de inclusão ao longo do período analisado. As universidades estaduais que deram início ao processo em 2002 e 2003, sofreram a ação do Legislativo (Uerj, Uenf, Uems) e foram referência para várias universidades se adiantarem na discussão interna para "não serem atropelados pelo Legislativo" nas palavras de um dos gestores entrevistados.

E quais foram as políticas pensadas? São três modalidades que se tornaram modelo seguido por todas as demais: a) Em primeiro lugar, foi pensado o acréscimo de vagas, especifico para a população indígena nas universidades estaduais do Paraná, em 2002, na realidade, a primeira ação afirmativa concebida, tornando-se o modelo desse público-alvo para as demais

\footnotetext{
${ }^{17} \mathrm{~A}$ preocupação não foi coletar a opinião dos entrevistados, mas sim de obter o registro do processo ocorrido. Para a descrição e apresentação dos resultados da pesquisa, ver os livros Entre dados e fatos: ação afirmativa no ensino superior (Paiva, 2011) e Ação afirmativa em questão: Brasil, Estados Unidos, França e África do Sul (Paiva, 2013). Os resultados da pesquisa quantitativa se encontram nesses dois livros e foram analisados por Elielma Ayres Machado.
} 
instituições; b) Em segundo lugar, e no mesmo ano, foi concebido o sistema de cotas para egressos da escola pública, negros e pessoas com deficiência em quatro universidades estaduais (modalidade mais usada); c) por último, em 2005, também uma universidade estadual, a Unicamp, concebe outra ação afirmativa, de acréscimo de pontos, tornando-se o modelo para várias outras (UFMG, USP, UFF, para citar algumas). Esses três modelos apresentam grande variação e a mesma universidade pode adotar as três modalidades descritas acima, como é o caso da UnB, com cotas para negros, acréscimo de vagas para indígenas e acréscimo de notas para residentes do interior.

Seria impossível trazer os dados detalhados da pesquisa na presente análise. De acordo com os itens do roteiro que foram planilhados para a análise, vai ser feita uma breve síntese daqueles pontos levantados espontaneamente pelos entrevistados e que foram predominantes nas entrevistas. Quando perguntados sobre como se deu o processo de implantação, os entrevistados apontaram para a confluência de alguns fatores: a vontade da reitoria de implementar ações afirmativas; realização de reuniões de discussão com palestras sobre a desigualdade racial; surgimento de grupos internos de professores que questionavam a função social da universidade pública e o sistema do vestibular. Em universidades com Núcleos de Estudos AfroBrasileiros consolidados, este foi um ponto a mais para a concretização da medida, acelerando o processo de adoção.

Segundo os entrevistados, não foi um processo fácil: houve reação velada de professores e de alunos, e o temor de se estar racializando o acesso à universidade era constante. Tanto assim que a decisão tirada na maioria das universidades foi de cotas ou pontos para alunos de escolas públicas, sendo a questão racial abandonada ou acrescentada ao de egressos da escola pública (a UnB inovou: adotou cotas para negros sem condições). Mas os entrevistados foram unânimes em afirmar que houve uma pedagogia no processo: passada a tensão inicial, ficou a constatação de que os beneficiários das ações afirmativas estavam tendo bom desempenho, não houve evasão maior, nem tampouco a racialização do campus.

No que se refere ao item do impacto da política, este está diretamente relacionado às novas dificuldades trazidas por esse "novo" aluno que chega sem o suporte familiar dos outros alunos: depende do transporte público, não pode pagar a alimentação diária, e tem defasagens na sua formação anterior. Assim, a universidade teve de pensar em políticas de permanência que possibilitassem a continuação na graduação desse aluno com bolsaspermanência. Um sentimento predominante, no entanto, foi a preocupação da oferta de ensino de qualidade para que houvesse a real integração desse novo 
estudante no mercado de trabalho, tornando a universidade o caminho efetivo (e perdido há décadas com a queda da qualidade do ensino público básico) para a promoção da integração e diversificação do alunado.

Outro impacto profundo foi a nova sociabilidade no campus, com o surgimento de discriminação velada, sem que muitas vezes se tornasse questão levada para os gestores. Mas também foi um processo de aprendizado para alunos e professores: a diversidade trazida com esse novo aluno foi avaliada de maneira positiva, depois de iniciado o processo. Aliás, a questão da diversidade trazida com os novos alunos - pobres, indígenas, negros, deficientes - foi um dos argumentos centrais na avaliação feita pelos profissionais ouvidos para a aceitação de políticas de ação afirmativa. Pode ser o início de um círculo mais virtuoso que possa reverter o ciclo perverso anterior, quando as universidades públicas recebiam, em média, $80 \%$ dos alunos da rede privada de ensino, barrando grande parte dos $80 \%$ dos que estudavam em escolas estaduais da rede pública.

$\mathrm{Na}$ realidade, as novas necessidades representaram o desafio mais mencionado: em especial, a tarefa de proporcionar a permanência dos beneficiários de ações afirmativas no campus. Porque surgiram problemas que anteriormente não existiam na mesma proporção: de locomoção, de moradia, de reforço em disciplinas, especialmente nos cursos de maior demanda. Mas como disse uma pró-reitora de escola de medicina, "agora temos de ensinar de verdade, pois antes nossos alunos vinham prontos dos melhores colégios". Os dois primeiros anos foram descritos como cruciais para a adaptação e continuação dos alunos de ações afirmativas. E é interessante acrescentar que muitos deles passaram da bolsa de permanência para bolsa de iniciação científica quando conseguem ultrapassar as dificuldades iniciais.

Quanto ao item prospecção, os entrevistados foram convidados a pensar acerca do futuro das políticas e das mudanças em curso em suas universidades. Era constante o sentimento de que as ações afirmativas haviam chegado para ficar, pese as tensões e oposições de docentes e discentes. Mas houve mais ceticismo quanto à adoção de ações afirmativas para negros. Foi bastante mencionada a resistência de se tomar decisão em torno da classificação racial, o que traz a discussão feita no início desse trabalho: apesar de ter sido a ação afirmativa no ensino superior uma demanda específica dos movimentos negros, a maior parte das universidades adotou, em decisão dos conselhos universitários, políticas para alunos egressos do ensino público, ficando a questão racial ou subsumida na questão social ou simplesmente não contemplada. Assim, a adoção da "cota social" ao invés da "cota racial", como definem os entrevistados as políticas de ação afirmativa para alunos da escola 
pública, foi a "política possível de consenso" alcançada, o que evidencia como é difícil lidar com a ideia de desigualdade racial brasileira, e como a ideia de "raça" como critério para a adoção de ações afirmativas representa um campo de muita tensão.

E para concluir esta breve síntese, cabe mencionar que várias das questões que têm estado no centro da discussão em torno das "cotas" há alguns anos se desmontam com a experiência das primeiras universidades que lá atrás, a partir de 2002, iniciaram sua adoção. Com as primeiras gerações de beneficiários das variadas políticas se formando nas universidades pioneiras, já é possível a análise da trajetória acadêmica desses alunos, tanto no que se refere ao desempenho escolar, quanto à possibilidade de permanência na universidade. E duas das apreensões iniciais - a existência de conflitos raciais e a queda da qualidade do ensino - se desfizeram. Segundo gestores das universidades com programas há alguns anos, estas questões já podem ser analisadas: a) os beneficiários das ações afirmativas não têm apresentado resultados inferiores, quando comparados aos alunos do vestibular universal, o que não comprometeu a qualidade dos cursos; b) não há existência de conflitos raciais nas universidades que adotaram algum tipo de política, pois a diversidade alcançada se sobrepôs aos problemas iniciais. Assim, as universidades públicas estão hoje mais diversas e começam a cumprir de maneira mais satisfatória sua função social de instituição de ensino público.

Estes são alguns dados de uma pesquisa realizada no exato momento em que as ações afirmativas eram pensadas a partir do consenso alcançado nos conselhos universitários. Os beneficiários de ações afirmativas eram, no final de 2011, a realidade em 71 das 96 universidades públicas federais e estaduais do país, cuja história começa a mudar em 2012, com a Lei 12.711/2012, que instituiu a obrigatoriedade de ações afirmativas nas universidades federais. Assim, há novo rearranjo na configuração da universidade pública brasileira (as estaduais de vários estados também têm sido instadas a pensar em políticas de inclusão).

Mas a mudança no campus provocada por políticas públicas não se iniciou em 2012. Em 2005, as universidades públicas começaram a perder alunos com o programa Universidade para Todos (ProUni), quando foi aberta a possibilidade de alunos de baixa renda pleitear a entrada em universidades privadas. Em 2007, surge o plano de reestruturação universitária (Reuni) programa que promoveu forte incentivo orçamentário às universidades federais quando estas aderiram a políticas de inclusão, dentre outros requisitos. Tais políticas trouxeram profunda mudança para a adoção de ações afirmativas. Tal efeito se mostra nos números: até 2006, havia 22 universidades estaduais e apenas 8 universidades federais com algum tipo de ações afirmativas; a 
partir de 2007, esse quadro se inverte e em apenas dois anos, 2007 e 2008, 18 universidades federais haviam adotado algum tipo de ações afirmativas e em 2011 eram a maioria: 39 federais e 32 estaduais.

\section{Considerações finais}

Pode-se perceber na análise feita acima, a transformação em curso nas práticas sociais com o processo de consolidação democrático do país. Parte expressiva da população brasileira, na análise trazida aqui a população negra, se organiza e passa a reivindicar demandas com um novo "script", que foge àquele do padrão de relações socais construído até então. Afinal, denunciam racismo e pedem ações efetivas que encurtem o abismo existente ao acesso aos bens sociais no que concerne à cor. Assim sendo, ainda que não se possa falar em um conceito biológico ou antropológico de raça, a raça na sua dimensão sociológica é uma importante categoria analítica para entender as novas reivindicações e a denúncia dos impedimentos estruturais para a plena integração de grande parcela da população. Certamente a questão da desigualdade brasileira não pode se restringir à questão da raça, mas é um fato que a mobilidade social para o branco pobre tem sido uma realidade mais concreta, como demonstrou Nelson do Valle e Silva (2000). ${ }^{18}$

Para finalizar, pode-se trazer o que dizia Honneth acerca da falta de reconhecimento na dimensão da solidariedade social. O não reconhecimento nessa dimensão resulta na falta de autoestima, impedimento para uma possível luta por reconhecimento. E aqui reside o perigo de uma equação perversa: a falta de autoestima aliada a relações hierárquicas resultou ao longo de nossa história republicana na aquiescência à subalternidade. É essa aquiescência que está sendo questionada, quando se cobra um projeto societário em que a solidariedade social se amplie a grupos que até muito recentemente ficavam no "outro" grupo de nossa cidadania disjuntiva. Pode ser um remédio efetivo para nossa esquizofrenia social: afinal, demandas por reconhecimento de diversos matizes estão postas na esfera pública, trazendo novas questões e novos conflitos. De qualquer forma, a ação afirmativa no ensino superior representa uma animação nas práticas sociais que pode ser um dos caminhos para novo exercício da cidadania em bases ampliadas, agora em uma chave de radicalidade democrática porquanto mais inclusiva e diferenciada.

Certamente não se está defendendo que a racialização da sociedade brasileira é o caminho, mas sim de que é necessário o reconhecimento da

\footnotetext{
${ }^{18} \mathrm{O}$ autor mostra que a mobilidade ocupacional intergeracional segundo a cor era, em 1996, maior para brancos $(52,5 \%)$ do que para pretos $(43,9 \%)$ e pardos $(45,5 \%)$.
} 
legitimidade das demandas desse novo ator social - o negro, que usa a cor como ação estratégica para a concertação social. Tampouco se pretende sugerir que os movimentos negros são expressões de virtude e que vão trazer todas as soluções para a desigualdade estrutural descrita acima. Mas sem dúvida alguma eles trazem novas questões que pedem reflexão e novas formas de negociação com o estado. E a ação afirmativa na universidade para negros, é, indiscutivelmente, uma de suas manifestações mais controversas: questionam não só o sistema tradicional de acesso ao ensino superior, o vestibular, como também pede a mudança de cor daqueles cursos que historicamente tinham uma "linha de cor" em seus bancos. Afinal, este é mesmo um dos resultados da implantação de qualquer política de ação afirmativa: acarreta impacto profundo e suscita grandes debates discursivos na esfera pública.

Concluindo, é preciso lembrar que o debate ocorrido nos espaços públicos acerca da implantação de ações afirmativas nas universidades públicas ficou evidenciado, em 2012, com a decisão unânime do Supremo Tribunal Federal a respeito da constitucionalidade das cotas raciais na UnB. As sentenças proferidas pelos juízes ressaltaram a discriminação, a desigualdade étnicoracial, a cor da pobreza, dentre as principais razões para legitimar a adoção de "cotas" para negros naquela universidade. E afirmaram que as cotas poderiam efetivamente trazer maior tolerância racial, reparação de desigualdades e o reconhecimento de injustiças históricas. As sentenças podem ser interpretadas, portanto, como o resultado alcançado nos espaços discursivos de que se falava acima: depois de uma década de troca de argumentação na esfera pública, a argumentação construída nesse período foi incorporada nas sentenças dos diversos juízes da Suprema Corte. Porque o tema das desigualdades racial e étnica esteve nos espaços públicos desde a redemocratização do país, suscitando debates acadêmicos, mobilizações sociais e posições na mídia, tema tão invisibilizado na sociedade brasileira por longo tempo e que hoje faz parte dos desafios de uma ordem democrática mais inclusiva.

\section{Referências}

ALBERTI, Verena; PEREIRA, Amilcar (orgs.). Histórias do movimento negro no Brasil. Rio de Janeiro: FGV, 2007.

APPIAH, K. Anthony. Identity, authenticity, survival. In: Amy Gutmann (org.). Multiculturalism. Princeton: The Princeton University Press, 1994. p. 149-163.

ARENDT, Hannah. A condição humana. Rio de Janeiro: Forense Universitária, 1983.

BARBOSA, Joaquim. Ação afirmativa e princípio constitucional da igualdade. Rio de Janeiro: Renovar, 2001. 
BENHABIB, Seyla. Models of public sphere: Hannah Arendt, the liberal tradition and Jürgen Habermas. In: Craic Calhoun (org.). Habermas and the public sphere. Massachusetts: The MIT Press, 1999. p. 73-98.

BOBBIO, Norberto. A era dos direitos. Rio de Janeiro: Campus, 1990.

CARVALHO, José Murilo. Os bestializados. São Paulo: Cia. Das Letras, 1991.

COSTA, Emília Viotti. Da monarquia à república: momentos decisivos. São Paulo: Grijalbo, 1977.

COSTA, Sérgio. As cores de Ercília. Belo Horizonte: Editora UFMG, 2002.

DaMATTA, Roberto. Relativizando. Rio de Janeiro: Rocco, 1993.

DAGNINO, Evelina. Os movimentos sociais e a emergência de uma nova cidadania. In: Evelina Dagnino (org.). Política e sociedade no Brasil. São Paulo: Brasiliense, 1994, p. 103-115.

FERNANDES, Florestan. A integração do negro na sociedade de classes. São Paulo: Ática, 1978.

FRASER, Nancy. Justice interrupts. New York: Routledge, 1997.

FRASER, Nancy. Redistribuição ou reconhecimento? Classe e status na sociedade contemporânea. Interseções. v. 4, n. 1, p. 7-32, 2002.

FRASER, Nancy; HONNETH, Axel. Redistribution or recognition? A politicalphilosophical exchange. New York: Verso, 2003.

FREYRE, Gilberto. Casa-grande e senzala. Rio de Janeiro: José Olympo, 1981.

GOHN, Maria da Glória. Movimentos sociais e redes de mobilizações civis no Brasil contemporâneo. Petrópolis: Vozes, 2010.

GONZALEZ, Lélia; HASENBALG, Carlos Alfredo. Lugar de negro. Rio de Janeiro: Marco Zero, 1982.

GUIMARÃES, Antonio Sérgio. Classes, raças e democracia. São Paulo: Editora 34, 2002.

GUIMARÃES, Antonio Sérgio. Racismo e anti-racismo no Brasil. São Paulo: Editora 34, 1999.

HABERMAS, Jürgen. Mudança estrutural na esfera pública. Rio de Janeiro: Tempo Brasileiro, 1984.

HALL, Stuart. A identidade cultural na pós-modernidade. Rio de Janeiro: DP\&A Ed., 2005.

HASENBALG, Carlos Alfredo. Discriminação e desigualdades raciais no Brasil. Rio de Janeiro: Editora Graal, 1979.

HASENBALG, Carlos; SILVA, Nelson do Valle. Relações raciais no Brasil contemporâneo. Rio de Janeiro: Rio Fundo Ed. 1992.

HASENBALG, Carlos; SILVA, Nelson do Valle. Origens e destinos. Rio de Janeiro: Topbooks, 2003. 
HERINGER, Rosana. Ação afirmativa e a promoção da igualdade racial no Brasil: o desafio da prática. In: Angela R. Paiva (org.). Ação afirmativa na universidade: reflexão sobre experiências concretas. Rio de Janeiro: Ed. PUC-Rio, 2004.

HENRIQUES, Ricardo. Raça e gênero nos sistemas de ensino. Brasília: Unesco, 2001.

HONNETH, Axel. A luta por reconhecimento. São Paulo: Editora 34, 2003.

MARSHALL, T. H. Cidadania, classe social e status. Rio de Janeiro: Zahar, 1967.

MATTOS, Patrícia. A sociologia politica do reconhecimento. São Paulo: Annablume 2006.

McADAM, Doug. Political process and the development of black insurgency. Chicago: The University of Chicago Press, 1999.

MEAD, G. H. Mind, self and society. Chicago; University of Chicago Press, 1964.

MEDEIROS, Carlos Alberto. Na lei e na raça: legislação e relações raciais BrasilEstados Unidos. Rio de Janeiro: DP\&A, 2004.

MELUCCI, Alberto. A invenção do presente. Petrópolis: Vozes, 2001.

NASCIMENTO, Abdias. Quilombismo: afrocentricidade: uma abordagem epistemológica inovadora. São Paulo: Sumus, 2009.

OLIVEIRA, Nythamar. Affirmative action, recognition and self-respect: Axel Honneth and the phenomenological deficit of critical theory. Civitas. v. 9, n. 3, p. 369-385, 2009 $<10.15448 / 1984-7289.2009 .3 .6897>$.

PAIVA, Angela R. Católico, protestante, cidadão. Belo Horizonte: UFMG Ed. 2003.

PAIVA, Angela R. A difícil equação entre modernidade e desigualdade. Interseções, v. 6, p. 7-17, 2004.

PAIVA, Angela R. (org.). Entre dados e fatos: ação afirmativa nas universidades públicas brasileiras. Rio de Janeiro: Pallas, 2010.

PAIVA, Angela R. Ação afirmativa em questão: Brasil, Estados Unidos, França e África do Sul. Rio de Janeiro: Pallas, 2013.

PEREIRA, Amauri M. Trajetórias e perspectivas do movimento negro brasileiro. Belo Horizonte: Nandyala, 2008.

PETRUCCELLI, José Luis. A cor denominada: estudos sobre a classificação étnicoracial. Rio de Janeiro: DP\&A, 2007.

REIS, Elisa P. Elites agrárias, state building e autoritarismo. Dados, v. 25, n, 3, p. 331-348, 1982.

RIBEIRO, Carlos Antonio C. Classe, raça e mobilidade social no Brasil. Dados, v. 49, n. 4, p. 833-873, $2006<10.1590 / \mathrm{S} 0011-52582006000400006>$.

RIBEIRO, Matilde. Políticas de promoção da igualdade racial no Brasil. Rio de Janeiro: Garamond, 2014.

SANSONE, Lívio. Cor, classe e modernidade em duas áreas da Bahia. Estudos Afro-Asiáticos, v. 23, n. 1, p. 143-173, 1993. 
SANTOS, Augusto Sales. Educação: um pensamento negro contemporâneo. São Paulo: Paco Editorial, 2014.

SANTOS, Renato E. Racialidade e novas formas de ação social: o pré-vestibular para negros e carentes. In: Renato Emerson dos Santos; Fátima Lobato (org.). Ações afirmativas: políticas públicas contra as desigualdades raciais. Rio de Janeiro: DP\&A, 2003. p. 127-153.

SANTOS, Wanderley G. Cidadania e justiça: a política social na ordem brasileira. Rio de Janeiro: Campus, 1979.

SCHARTZMAN, Luisa F.; SILVA, Graziella M. Dias da. Unexpected narratives from multicultural policies: translations of affirmative action in Brazil. Journal of Latin American and Caribbean Ethnic Studies, v. 7, n. 1, p. 31-48, 2012 $<10.1080 / 17442222.2012 .658295>$.

SCHWARZ, Roberto. As ideias fora do lugar. In: Roberto Schwarz. Ao vencedor as batatas. São Paulo: Livraria Duas Cidades, 1992.

SEYFERTH, Giralda. Construindo a nação: hierarquias raciais e o papel do racismo nas políticas de imigração e colonização. In: Marcos Chor Maio; Ricardo Ventura (orgs.). Raça, ciência e sociedade. Rio de Janeiro: Fiocruz Editora, 1996. p. 41-58.

SILVA, Nelson do Valle. Extensão e natureza das desigualdades raciais no Brasil. In: Antonio Sérgio Alfredo Guimarães; Lynn Huntley (orgs.). Tirando a máscara: ensaios sobre o racismo no Brasil. São Paulo: Paz e Terra, 2000. p. 33-51.

SOUZA, Jessé. A modernização seletiva. Brasília: Editora UnB, 2000.

TARROW, Sidney. Power in movement. New York: Cambridge University Press, 1998.

TAYLOR, Charles. The politics of recognition. In: Amy Gutmann (org.). Multiculturalism: examining the politics of recognition. Princeton: The Princeton University Press, 1994. p. 25-73.

TELLES, Vera S. Sociedade civil e a construção de espaços públicos. In: Eveline Dagnino (org.). Anos 90: política e sociedade no Brasil. São Paulo: Brasiliense, 1994. p. 91-102.

VELHO, Gilberto. Violência, reciprocidade e desigualdade: uma perspectiva antropológica. In: Gilberto Velho; Marcos Alvito (orgs.). Cidadania e violência. Rio de Janeiro: FGV, 1996. p. 11-25.

WERNECK VIANNA, Luiz. A revolução passiva. Rio de Janeiro: Revan, 1997.

YOUNG, Iris M. Polity and group difference: a critique of the ideal of universal citizenship. Ethics, v. 99, n. 2, p. 250-274, $1989<10.1086 / 293065>$.

Recebido em: 18 maio 2015

Aprovado em: $1^{\circ}$ dez. 2015

Autora correspondente:

Angela Randolpho Paiva

Rua Marquês de São Vicente, 225 - Vila dos Diretórios, casa 18 - Gávea

22451-900 Rio de Janeiro, RJ, Brasil 